\title{
La mujer en la publicidad televisiva de alimentos en Chile: una aproximación feminista desde el análisis argumental del discurso*
}

\author{
Women in television food advertising in Chile: a feminist \\ argumentative discourse analysis approach
}

\section{Carolina Godoy}

Universidad de La Frontera, Temuco, Chile Universidad Autónoma de Chile

c.godoy11aufromail.cl

\section{Berta Schnettler}

Universidad de La Frontera, Temuco, Chile berta.schnettlerQufrontera.cl

\section{Resumen}

El objetivo del estudio es analizar el modo en que discursivamente se construye la categoría mujer a partir de anuncios publicitarios ligados a la alimentación. Se recurre al análisis argumental para indagar desde un enfoque discursivo y feminista el rol que aparece ligado a la mujer en la publicidad de alimentos. Se realizó el análisis de 15 anuncios difundidos en los principales medios de televisión abierta de Chile. Los resultados develaron la articulación discursiva de tres dimensiones propias del colonialismo y de las formas de clasificación social asociadas a la mujer en la televisión de la era digital: control de las relaciones sociales, familia burguesa y negación del rol productivo de la mujer.

Palabras Claves: Análisis de discurso, colonialismo, mujer, publicidad de alimentos

\section{Marianela Denegri}

Universidad de La Frontera, Temuco, Chile marianela.denegridufrontera.cl

\section{Mauricio Alarcón}

Universidad de La Frontera, Temuco, Chile m.alarcon11dufromail.cl
Key words: discourse analysis, colonialism, women, food advertising

* Agradecimientos: Al Fondo Nacional de Desarrollo Científico y Tecnológico (FONDECYT) por financiamiento otorgado al proyecto $\mathrm{N}^{\circ} 1160005$ 


\section{Introducción}

La televisión como medio de comunicación se está transformando para adaptarse a las nuevas condiciones de los contextos digitales y a los retos que implica la sociedad multipantalla (Jódar, 2010; Pérez, 2008). Sufre una mediamorfosis donde "los nuevos medios aparecen gradualmente por la metamorfosis de los medios antiguos. Cuando emergen nuevas formas de comunicación, las antiguas generalmente no mueren, sino que continúan evolucionando y adaptándose" (Fidler, 1998, p. 57). Por lo tanto sigue siendo un actor socio-cultural relevante, situado históricamente y que asume cada vez más un aspecto multifacético y cambiante. Su acción se enmarca "en una compleja red de interacciones y mediaciones socio-culturales y políticas, en las que se produce la construcción de imaginarios colectivos y de producción discursiva que se sedimenta como sentido común" (Santa Cruz, 2017, p.9).

Para Pedraza (2009) la televisión contribuye a la consolidación de un régimen estético político que se instaura a partir de las nociones de subjetividad y corporalidad como expresiones de la norma humana contemporánea. En su dimensión política y económica dicho proceso aparece sustentado a partir de la diada capitalismo/modernidad. El colonialismo en la era del desarrollo digital, opera bajo una nueva estructura tecnológica que imbrica relaciones de poder y medios de comunicación, donde se socializa y normaliza toda una política del cuerpo.

Al respecto cabe preguntarse: ¿el desarrollo tecnológico y digital habrá generado un cambio en la construcción del cuerpo de la mujer que se socializa en la televisión? 0 bien, como lo plantean Cáceres, Ruiz \& Brändle (2011): ¿podría tratarse del surgimiento de nuevas pantallas para mantener viejas prácticas?. Responder a esta pregunta implica desentrañar cómo opera la construcción de la categoría mujer en la televisión de la era digital. Para ello, se analizan los argumentos presentes en los anuncios publicitarios ligados a la alimentación en Chile emitidos entre junio y agosto del año 2018.

A modo de supuesto la investigación plantea que bajo el discurso publicitario sigue operando una visión patriarcal y colonialista asociada a la mu- jer. Planteamientos radicales que consideran que en la cibercultura no sólo no se han cambiado los estereotipos de género, sino que han acentuado la discriminación y la opresión hacia las mujeres (Arias \& Sánchez, 2017).

\section{Marco Teórico}

\subsection{Colonialismo, discurso y mujer}

La producción de la mujer del tercer mundo como sujeto monolítico se origina y se mantiene a partir de una colonización predominantemente discursiva (Mohanty, 2008). Colonización entendida como concepto que permite describir las jerarquías económicas y políticas implícitas en la producción de un discurso que plantea un sistema de control de las relaciones intersubjetivas (Quintero, 2013).

De esta forma al interior del discurso colonialista, en el control del trabajo, de sus recursos y de sus productos, está la empresa capitalista. En el control del sexo está la familia burguesa, en el control de la autoridad el Estado-nación y en el control de la intersubjetividad, el eurocentrismo. Cada una de esas instituciones existe en relaciones de interdependencia con cada una de las otras, por lo cual el patrón de poder está configurado como un sistema (Quijano, 2000).

Esta dinámica se vio sustentada con la expansión del capitalismo y de la burguesía, por cuanto en su seno proliferaron los discursos orientados a activar formas corporales que estimularan los principios de productividad, salud, gobernabilidad y emocionalidad (Pedraza, 2009). Para Cobo (2015) es en este proceso de un mercado libre en el que se ha entendido que los cuerpos de las mujeres son una mercancía de la que se extraen plusvalías necesarias para la reproducción social de los patriarcados contemporáneos.

Este análisis es posible hacerlo evidente en aquellos mensajes que reproducen el modelo económico. La publicidad constituye una forma de discurso argumentativo que recrea un ordenamiento de género específico (Castillo, 2006). Es un acto performativo que construye una corporalidad, roles sociales y con ello una categoría de mujer (Muñiz, 2014). 
Giménez (1981) entiende por discurso toda práctica enunciativa considerada en función de sus condiciones sociales, institucionales e históricas coyunturales de producción. El autor, destaca tres funciones del discurso: informar, expresar y argumentar. Si bien, las tres funciones siempre están relacionadas, la función argumentativa es la que domina siempre, en tanto que, "toda argumentación pone en juego una determinada estructura retórica-discursiva en la medida que selecciona y ordena determinadas operaciones lógico-semánticas en función de un objetivo muy preciso" (1981, p. 145).

Para Thompson (1998) quien define discurso como forma simbólica, incluye un amplio campo de fenómenos significativos (desde las acciones hasta los enunciados, los textos, los programas de televisión y las obras de arte). Reconoce en dicha definición que el carácter ideológico de las formas sirve para establecer las relaciones de dominación. Para Giménez, el proceso de argumentación "transforma el lenguaje lingüístico en ideología, el emisor del mensaje se apropia de hechos, objetos, situaciones, valores para elaborar, técnica y sutilmente un proceso de sujeción de normalización de las relaciones sociales" (1981, p.145).

\subsection{Discurso publicitario, mujer y alimentación}

La publicidad es un tipo de discurso argumentativo (Márquez, 2007; Giménez, 1981) pues a la base de sus determinaciones predicativas opera una ideología persuasiva (Loscertales \& Núñez, 2009; Giménez, 1981), respecto de lo que en este caso, alimentariamente debe consumirme, y para ello se vale de ciertas imágenes estereotipadas de hombres y mujeres.

Según Caro (2014) la función que desempeña la publicidad en el marco del capitalismo es dotar a los productos de una significación, que lejos de cumplir con una función anunciadora, implica una producción semiótica de la mercancía. Denomina a este fenómeno que vincula signo-mercancía como "publicidad de la significación", cuyo objetivo es "enunciar" marcas donde la trascendencia resulta a partir de ese momento indiscernible de su propia enunciación publicitaria (Caro, 2014).
Desde una perspectiva feminista, podemos evidenciar los efectos de la significación al observar el carácter performativo de los anuncios publicitarios. Para Butler (2004) la reiteración discursiva provee de un campo de significaciones que se convierten en normas que determinan a los sujetos en base a una legalidad que organiza al mundo en torno a un binarismo cisgénero. En la performatividad de género, se anula la participación de lo biológico en la definición del sexo, esto hace centrar la discusión exclusivamente en el lenguaje como constructor de prácticas culturales y sociales, modalidades de expresiones que producen aquello que enuncia (Butler, 2002).

En la publicidad de alimentos se evidencian claramente las significaciones dadas a la corporalidad, a los roles de género y a la vida saludable. Díaz-Méndez y González-Álvarez (2013) mediante un estudio realizado, señalan que los problemas alimentarios actuales van ligados a los mensajes discursivos sobre el mantenimiento de la salud, al ideal de belleza y al control del cuerpo.

Cabrera (2010) al realizar un análisis al cuerpo femenino en la publicidad, concluye que los cánones de belleza son restrictivos y nocivos para la salud, donde el atributo físico de la delgadez es el más valorado. Para Muñiz: "Las prácticas de belleza son centrales en la reproducción de relaciones de dominación, al perpetuar los efectos disciplinarios de la feminidad" (2014, p.430).

Velandía \& Rincón (2013) mediante un estudio realizado en Colombia identificaron las representaciones y estereotipos de género utilizados en los comerciales transmitidos por televisión, los resultados evidenciaron diferencias en el trato del género, apareciendo más figuras femeninas en escenarios privados y masculinas en lugares públicos. Se comprobó la utilización de estereotipos de mujer sexy y ama de casa, como representaciones femeninas de objeto decorativo o en roles de dependencia.

Espinar \& González (2012) mediante un análisis de contenido realizado a la publicidad de alimentos, concluyeron que no solo se perpetúan los estereotipos de géreno mediante los protagonistas de los anuncios sino que también a través de sus narradores. Locertales y Núñez (2009), plantean que los principales estereotipos identificados en la pu- 
blicidad reproducen un estereotipo de rasgo, que impregna las consideraciones sobre las mujeres en general. Para Ribas y Todolí (2008) la relevancia que cumplen los estereotipos es que siguen funcionando en la organización del imaginario colectivo mediante la difusión de anuncios publicitarios bajo la metáfora de la mujer objeto.

En Chile son escasos los trabajos académicos sobre publicidad que caractericen a las agencias o a sus anuncios (Repiso, Fernández \& Lloves, 2015). Como parte de las pocas evidencias empíricas encontradas, destaca un estudio realizado por Uribe, Manzur, Hidalgo \& Fernández (2008) quienes analizaron la presencia de estereotipación de género en una muestra de publicidad gráfica chilena. Los resultados indicaron que la publicidad asocia a las mujeres a productos de belleza y cuidado personal, a mayor dependencia emocional, a tener un promedio de edad más bajo que los hombres y a exhibir más el cuerpo que éstos.

En un estudio comparado sobre los estereotipos étnicos dominantes en los sistemas televisivos de Chile y Francia, Amigo, Bravo, Sécail, Lefébure \& Borrell (2016) concluyeron que en el caso francés se da una subrepresentación de las denominadas minorías étnicas no blancas. Para el caso chileno se observó una tensión entre la autodefinición implícita como sociedad blanca y el hecho de que las personas representadas en la televisión son más blancos que la mayoría de la población.

Desde esta perspectiva, visualizamos una doble complejidad asociada al cuerpo de la mujer al interior del discurso publicitario. Por un lado, el cuerpo se convierte en un objeto pasivo incapaz de comunicar por sí mismo, al servicio de las pautas marcadas por los medios acerca de la moda, la belleza o la aceptación social (Márquez, 2007). Por otro lado, se comporta como "objeto semiótico, en tanto que es representado mediante diversos lenguajes" (Duch \& Mèlich, 2000, p.245), en este caso por el poder ideológico colonialista que encierra el discurso publicitario en torno a la alimentación y al cuerpo.

\section{Material y métodos}

Bajo los anteriores antecedentes se fundamenta el objetivo de esta investigación el cual busca analizar el modo en que discursivamente se construye una categoría de mujer a partir de anuncios publicitarios televisivos ligados a la alimentación. Navarro y Marín (2013) a partir de un análisis bibliométrico realizado a la producción científica sobre sexismo publicitarios desde el año 1988 al 2010, indican que se ha estudiado principalmente el sexismo en medios impresos por sobre los audiovisuales. Asimismo, Espinar y González (2012) plantean que la mayoría de estas investigaciones han optado por aplicar la perspectiva cuantitativa del análisis de contenido, por sobre métodos cualitativos como lo es el uso del análisis argumental del discurso. Ahora, respecto del estudio de los anuncios publicitarios sobre alimentación, Royo-Vela, Aldas-Manzano, Küster \& Vila (2008), señalan que generalmente éstos no han sido relacionados con el género. Más aún, escasamente han sido objetivo de investigación en el análisis de representaciones de género, pues se han enfocado más en estudiar su asociación en referencia a transmisión de hábitos alimentarios (Espinar \& González, 2012).

La principal contribución de este estudio radica en aportar conocimientos respecto de la construcción de la categoría mujer mediante un diseño metodológico que analiza discursivamente la lógica argumental y sintagmática presente en anuncios publicitarios televisivos sobre alimentación. Colaborando con el reconocimiento de las estructuras predicativas y gramaticales productoras de significación, así como también del sentido de la secuencia de signos y enunciaciones que se articulan para la producción de la categoría mujer.

\subsection{Diseño}

Se optó por un tipo de investigación cualitativa que buscó mediante un análisis argumental del discurso (Giménez, 1981) analizar la construcción de la categoría mujer en anuncios publicitarios televisivos sobre alimentación. 


\subsection{Corpus de estudio}

La selección del corpus de estudio fue de forma intencionada, empleando criterios de inclusión. En primer lugar, se procedió a escoger la franja publicitaria con mayor consumo televisivo, lo que de acuerdo con datos aportados por el anuario estadístico del Consejo Nacional de Televisión (CNTV) del año 2016, correspondió a la franja de la mañana (entre las 08:00 y 12:00 hrs.) con un $36,9 \%$ de las preferencias. Posteriormente, se seleccionaron los cuatro canales de televisión abierta con mayor audiencia en la franja matinal: TVN, Mega, Chilevisión y Canal 13.

Si bien, todos los canales seleccionados son miembros de la Asociación Nacional de Televisión (ANATEL) cada uno de ellos tiene orígenes y una trayectoria distinta. Televisión Nacional de Chile es el único servicio de televisión pública. Fue creado el 31 de enero de 1969. En la actualidad cuenta con 9 centros regionales ubicados en las principales ciudades de Chile, los cuales producen programación local exclusiva para sus zonas de emisión. Megavisión, comienza sus transmisiones en 1990 y se convierte en la primera empresa de comunicaciones que responde al desafío de la televisión privada en Chile. Canal 13 es una empresa de propiedad privada, que inició sus emisiones el 21 de agosto de 1959 al amparo de la Pontificia Universidad Católica de Chile. Por último, Chilevisión inició sus transmisiones el 4 de noviembre de 1960, actualmente es de propiedad privada y es considerada la tercera red de televisión más antigua del país. Es relevante mencionar que los cuatro canales transmiten en la franja de la mañana de forma simultánea, programas que tienen un formato y duración similar (matinales). Asimismo, se reiteran en los espacios publicitarios, la misma tipología de anuncios publicitarios sobre alimentación.

Con base a los canales y horario seleccionado, se procedió durante los meses de junio a agosto del año 2018 a catastrar los anuncios publicitarios sobre alimentación donde aparecieran mujeres. En total se registraron 15 anuncios asociados a las categorías alimentarias de carnes, lácteos, harinas, fruitivos, condimentos, azúcares y suplementos alimenticios. A continuación, la tabla $N^{\circ} 1$ detalla el corpus analizado:

Del total catastrado, ocho productos responden a la categoría de lácteos en sus distintas modalidades; yogurt, postres y leches. Los otros, a excepción de las harinas, se presentaron en categorías diferentes y únicas.

Tabla $N^{\circ} 1$ : Anuncios publicitarios catastrados

\begin{tabular}{|c|l|l|l|l|l|}
\hline$N^{0}$ & $\begin{array}{l}\text { Categoría } \\
\text { alimentaria }\end{array}$ & Temática general & Marca & Duración & $\begin{array}{l}\text { Tipo de mujer } \\
\text { que aparece }\end{array}$ \\
\hline 1 & Harinas & Pasta & Lucchetti & 30 seg. & Madre y esposa joven \\
\hline 2 & Lácteos & Yogurt & Soprole griego & 30 seg. & Mujeres jóvenes \\
\hline 3 & Lácteos & Yogurt Light & Colún & 17 seg. & Mujer joven \\
\hline 4 & Lácteos & Complemento alimenticio para adulto & $\begin{array}{l}\text { Ensure } \\
\text { Advanced }\end{array}$ & 30 seg. & Mujer adulta \\
\hline 5 & Lácteos & Leche para niños & Nido & 30 seg. & Madre joven \\
\hline 6 & $\begin{array}{l}\text { Suplementos } \\
\text { alimenticios }\end{array}$ & Complemento alimenticio para adulto & Glucerna & 20 seg. & Mujer joven \\
\hline 7 & Lácteos & Leche para adultos y niños & Pediasure & 20 seg. & Madre joven \\
\hline 8 & Azúcares & Azúcar light & lansa & 31 seg. & Madre y esposa \\
\hline 9 & Lácteos & Yogurt & Soprole & 45 seg. & Mujeres jóvenes \\
\hline 10 & Fruitivos & Té & Lipton & 31 seg. & Mujer adulta \\
\hline 11 & Lácteos & Postre & Chandelle & 31 seg. & Mujer joven \\
\hline 12 & Carnes & Pollo & Super Pollo & 32 seg. & Abuelita activa \\
\hline 13 & Harinas & Pastas para sopa & Lucchetti & 30 seg. & Madre joven \\
\hline 14 & Condimentos & Concentrado para cocinar & Maggi & 24 seg. & Mujer adulta \\
\hline 15 & Lácteos & Leche para niños & Similac & 29 seg. & Madre joven \\
\hline
\end{tabular}

Fuente: Elaboración propia. 


\subsection{Categorías de estudio}

La categoría de mujer se operacionalizó como una forma de clasificación binaria propia del colonialismo patriarcal que está estructurada por tres objetos discursivos: negación del rol productivo, control de las relaciones sociales y familia burguesa, los que a su vez se definen de la siguiente manera:

1. Control de las relaciones sociales: conjunto de dispositivos que enmarcan y regulan la normalidad social desde una lógica neoliberal.

2. Familia Burguesa: institución patriarcal coherente a los intereses del modelo económico capitalista, que define roles tradicionales para sus integrantes.

3. Negación del rol productivo de la mujer: imposición social respecto de roles de género que aseguran la reproducción del orden social y material de la familia burguesa.

Al mismo tiempo estos objetos discursivos fueron evidenciables a partir de aspectos morfológicos, narratológicos y comunicativos presentes en los anuncios publicitarios. Para dicho efecto se completó una matriz (basada en Giménez,1981; Del Valle, 2015-2019) que permitió mediante una observación visual y sistemática inventariar los argumentos presentes en los 15 anuncios publicitarios.

\subsubsection{Primera etapa}

Consistió en el reconocimiento e identificación de los argumentos presentes en los 15 anuncios publicitarios en función de los tres objetos discursivos (tabla N²). Los argumentos "son determinaciones predicativas que definen y dan contenido a objetos discursivos, atribuyéndoles determinados aspectos, características y funciones" (Giménez, 1981, p.145). Además, se pueden presentar en forma de enunciados modalizados, los que "desempeñan un papel importante en las estrategias argumentativas y que pueden definirse como la manera en que el sujeto de enunciación se relaciona con su propia enunciación o con el destinatario de su enunciado". Señala Giménez la existencia de variadas formas de enunciados modalizados: categorías de aserción lafirmación, negación e interrogación), categorías de certeza (cierto, probable), modalizaciones deónticas (deber ser), modalizaciones factitivas (hacer), modalizaciones de veridicción (parece que, es verdad que).

Complementando lo anterior, Greimas y Courtés definen modalización como "la producción de un enunciado que sobre determina a un enunciadodescriptivo. Por su parte el predicado modal puede ser definido, únicamente por su función táxica, por su finalidad transitiva, capaz de alcanzar otro enunciado tomado como objeto" (1982, p.262). Para la presentación de resultados, este análisis se ilustrará en la tabla $\mathrm{N}^{\circ} 4$.

\subsection{Metodología para análisis argumental de discurso}

Para el análisis del corpus de estudio se procedió a realizar un análisis sintagmático, el cual se desarrolló en tres fases.

Tabla N²: Operacionalización de la categoría de mujer

\begin{tabular}{|l|l|l|}
\hline Dimensiones generales & Criterios de observación & Argumentaciones \\
\hline \multirow{4}{*}{ Mirada: Aspectos morfológicos } & Expresiones de género & \\
\cline { 2 - 3 } & Representaciones de género & \\
\cline { 2 - 3 } & Funcionalidad de género & \\
\hline \multirow{4}{*}{ Visualidad: Aspectos narratológicos } & Rol de actores & \\
\cline { 2 - 3 } & Espacio/tiempo & \\
\cline { 2 - 3 } & Contexto simbólico & \\
\hline Imagen: Aspectos comunicativos & Nivel verbo visual & \\
\hline
\end{tabular}




\subsubsection{Segunda etapa}

Consistió en explicitar la gramática del argumento. Para ello, Giménez propone seleccionar los argumentos pivotes del discurso, que dan cuenta de relaciones lógicas de asociación entre argumentos lequivalencia, implicación, consecuencia, complemento, unión) o de disociación (incompatibilidad, exclusión, oposición, diferencia, discriminación). Para lograr dicho análisis fue necesario reagrupar los argumentos, lo cual se presenta en la tabla N5.

\subsubsection{Tercera etapa}

Implicó representar la estrategia discursiva. Para ello se seleccionaron y ordenaron las operaciones lógicas y modales aplicadas a las series de argumentos de acuerdo a sus objetos discursivos. Los resultados de esta etapa se presentan en la figura No1.

\section{Resultados}

La tabla $\mathrm{N}^{\circ} 3$ presenta una descripción general y sintética de los casos de estudio en función de sus construcciones morfológicas, narrativas y comunicacionales.

\subsection{Reconocimiento de argumentos}

En esta fase se procedió, con la ayuda de la matriz anteriormente presentada en la tabla $\mathrm{N}^{\circ} 2$, a inventariar cada uno de los argumentos según su aparición en los anuncios publicitarios, reconociendo al mismo tiempo su naturaleza enunciativa. La tabla $\mathrm{N}^{\circ} 4$ evidencia que el objeto discursivo denominado control de las relaciones sociales, registra una mayor cantidad de argumentaciones, las que se caracterizan por ser modalizaciones de asersión, veridicción, deónticas, factitivas y de certeza.

Dichos argumentos expresan los rasgos que deben tener las mujeres en la sociedad: ser madres, ser jóvenes, delgadas, sanas, bellas y vitales. También

Tabla $N^{\circ}$ 3: Descripción general de los casos de estudios

\begin{tabular}{|c|c|c|}
\hline Dimensiones generales & Criterios de observación & Descripción general \\
\hline \multirow[t]{3}{*}{$\begin{array}{l}\text { Mirada: Aspectos } \\
\text { morfológicos }\end{array}$} & Expresiones de género & $\begin{array}{l}\text { Los anuncios muestran a una mujer muy cariñosa y } \\
\text { feliz. En su rol de esposa y madre, preocupada por la } \\
\text { alimentación, compra y preparación de la comida. }\end{array}$ \\
\hline & Representaciones de género & $\begin{array}{l}\text { Aparece una mujer con un cuerpo } \\
\text { que es activo, delgado y jovial. }\end{array}$ \\
\hline & Funcionalidad de género & $\begin{array}{l}\text { Se asocia género femenino con la socialización } \\
\text { familiar y alimentaria, excluyendo de } \\
\text { este rol al género masculino. }\end{array}$ \\
\hline \multirow[t]{3}{*}{$\begin{array}{l}\text { Visualidad: Aspectos } \\
\text { narratológicos }\end{array}$} & Rol de actores & $\begin{array}{l}\text { Como actores principales aparecen madres, esposas } \\
\text { o abuelas. Así también los hijos y/o nietos. En un } \\
\text { rol más secundario aparecen los hombres. }\end{array}$ \\
\hline & Espacio/tiempo & $\begin{array}{l}\text { Aparece el mundo privado, hogares biparentales de } \\
\text { nivel socioeconómico alto. Los principales espacios } \\
\text { que se muestran son la cocina y el comedor. } \\
\text { Respecto del espacio público aparece el colegio. }\end{array}$ \\
\hline & Contexto simbólico & $\begin{array}{l}\text { El hogar se muestra como un espacio para } \\
\text { ser feliz y poder desarrollarse plenamente. } \\
\text { El contexto aparenta normalidad nutricional y } \\
\text { estética. La figura masculina no aparece ligada a } \\
\text { la crianza ni a la preparación de los alimentos. }\end{array}$ \\
\hline $\begin{array}{l}\text { Imagen: Aspectos } \\
\text { comunicativos }\end{array}$ & Nivel verbo visual & $\begin{array}{l}\text { Se reitera en la publicidad el slogan de alimenta con } \\
\text { cariño, utilizando a ambos como sinónimos. Por lo } \\
\text { demás la mujer aparece como la encargada de dar } \\
\text { cariño/alimentación. Así también se comunica que la } \\
\text { alimentación es la base para una vida saludable y feliz. }\end{array}$ \\
\hline
\end{tabular}

Fuente: Elaboración propia. 
aparecen las funciones afectivas y de cuidado familiar que deben desempeñar. Respecto del objeto discursivo, familia burguesa, los argumentos se orientan hacia el reconocimiento de la familia de clase socioeconómica alta, tradicional y estereotipada. Se ubica a la mujer en el espacio privado, orientada específicamente hacia el cumplimiento de labores de crianza y de alimentación. Por último, el objeto discursivo asociado a la negación del rol productivo de la mujer, se refuerza la insistencia en el cumplimiento de roles exclusivamente reproductivos (como el ser madre, ser abuela y cocinar).

\subsection{La explicitación de la gramática}

En esta fase se reagruparon los argumentos presentados en la tabla $\mathrm{N}^{\circ} 4$, identificando puntos nodales en el discurso que sostienen al resto de los argumentos (tabla $\mathrm{N}^{\circ}$ ). Luego, de forma descriptiva se presentan las relaciones de asociación y disociación de los argumentos pivotales.

De acuerdo con Giménez, las relaciones de asociación pueden estar dadas por: equivalencia, implicación, consecuencia, complementación y unión.

Tabla $\mathrm{N}^{\circ} 4$ : síntesis argumentos según objetos discursivos

\begin{tabular}{|c|c|c|}
\hline $\begin{array}{l}\text { Objetos } \\
\text { discursivos }\end{array}$ & Argumentos & Naturaleza del enunciado \\
\hline \multirow[t]{5}{*}{$\begin{array}{l}\text { Control } \\
\text { de las } \\
\text { relaciones } \\
\text { sociales }\end{array}$} & $\begin{array}{l}\text { 1. La mujer es joven y con un cuerpo delgado. } \\
\text { 2. La mujer es vitalidad } \\
\text { 3. Niños deben complementar su alimentación } \\
\text { 4. El alimento es cariño } \\
\text { 5. Cocinar es innovar } \\
\text { 6. Cocinar es felicidad }\end{array}$ & $\begin{array}{l}\text { Asersión: } \\
\text { Enunciados como afirmaciones. }\end{array}$ \\
\hline & $\begin{array}{l}\text { 7. La mujer es feliz en su rol de madre y esposa } \\
\text { 8. Cocinar se relaciona con dar amor. } \\
\text { 9. Ser mujer se relaciona con cocinar } \\
\text { 10. Cocinar se relaciona con cuidar a los hijos } \\
\text { 11. Para los niños su madre es lo más importante } \\
\text { 12. El hogar y colegio como espacio de desarrollo } \\
\text { 13. Niños, hombres y mujeres asociados a } \\
\text { normalidad nutricional y estética. }\end{array}$ & $\begin{array}{l}\text { Veridicción: } \\
\text { Enunciados como verdaderos. }\end{array}$ \\
\hline & $\begin{array}{l}\text { 14. Ser mujer se relaciona con ser mamá } \\
\text { 15. Madres siempre preocupadas por sus hijos } \\
\text { 16. Madre debe preocuparse por el crecimiento de sus hijos } \\
\text { 17. Mujer debe preocuparse por su salud } \\
\text { 18. Madre enseña valores a sus hijos }\end{array}$ & $\begin{array}{l}\text { Deóntico: } \\
\text { Enunciados que implican deber ser. }\end{array}$ \\
\hline & $\begin{array}{l}\text { 19. Madres dueñas del espacio privado } \\
\text { 20. Mujer requiere complementar su alimentación } \\
\text { 21. Mujer requiere tener más energía }\end{array}$ & $\begin{array}{l}\text { Certeza: } \\
\text { Enunciados como ciertos } \\
\text { o probables. }\end{array}$ \\
\hline & $\begin{array}{l}\text { 22. Abuelas son activas y aventureras } \\
\text { 23. Para cocinar se usan redes sociales } \\
\text { 24. Mujer debe consumir alimentos light }\end{array}$ & $\begin{array}{l}\text { Factitivo: } \\
\text { Enunciados que implican hacer. }\end{array}$ \\
\hline \multirow[t]{2}{*}{$\begin{array}{l}\text { Familia } \\
\text { burguesa }\end{array}$} & $\begin{array}{l}\text { 1. La mujer decide que alimentos comprar } \\
\text { 2. La mujer decide que cocinar } \\
\text { 3. El hogar tiene espacios luminosos y amplios } \\
\text { 4. Las mujeres son del nivel socioeconómico alto } \\
\text { 5. El hogar es el principal espacio de la mujer } \\
\text { 6. La familia disfruta de comidas }\end{array}$ & $\begin{array}{l}\text { Asersión: } \\
\text { Enunciados como afirmaciones. }\end{array}$ \\
\hline & $\begin{array}{l}\text { 7. La madre es una mujer joven } \\
\text { 8. La mujer debe cuidar de su familia }\end{array}$ & $\begin{array}{l}\text { Deóntico: } \\
\text { Enunciados como deber ser }\end{array}$ \\
\hline \multirow{3}{*}{$\begin{array}{l}\text { Negación } \\
\text { del rol } \\
\text { productivo } \\
\text { de la mujer }\end{array}$} & 1. La mujer es mamá o abuela & $\begin{array}{l}\text { Veridicción: } \\
\text { Enunciados como verdaderos. }\end{array}$ \\
\hline & $\begin{array}{l}\text { 2. La mujer está en su hogar } \\
\text { 3. La mujer está en la cocina } \\
\text { 4. La mujer tiene hijos } \\
\text { 5. Los hijos prefieren estar con su mamá }\end{array}$ & $\begin{array}{l}\text { Deóntico: } \\
\text { Enunciados como deber ser. }\end{array}$ \\
\hline & 6. La mujer acompaña al colegio a sus hijos & $\begin{array}{l}\text { Factitivo: } \\
\text { Enunciados que implican hacer. }\end{array}$ \\
\hline
\end{tabular}


Tabla N5: Argumentos pivotes

\begin{tabular}{|l|l|}
\hline $\begin{array}{l}\text { Objetos } \\
\text { discursivos }\end{array}$ & Argumentos pivotes \\
\hline $\begin{array}{l}\text { Control } \\
\text { de las } \\
\text { relaciones } \\
\text { sociales }\end{array}$ & $\begin{array}{l}\text { 1. Imagen corporal de la mujer: argumentos que refieren al cuerpo de la mujer, cuerpo bello, } \\
\text { sano y joven. } \\
\text { 2on les sociales en la alimentación: argumentos que plantean la vinculación entre el ser mujer } \\
\text { 3. La escuela y hogar: argumentos que establecen la importancia de la escuela y la casa como } \\
\text { espacios de desarrollo para niños. } \\
\text { 4. Normalidad nutricional y estética: argumentos que establecen la importancia del cuidado de la } \\
\text { salud y estética, del consumo de alimentos light y suplementos alimenticios para estar dentro } \\
\text { de la normalidad esperada. } \\
\text { 5. Rol de redes sociales: argumentos que plantean la necesidad de innovar en la cocina. }\end{array}$ \\
\hline $\begin{array}{l}\text { Familia } \\
\text { burguesa }\end{array}$ & $\begin{array}{l}\text { 1. Mujer y clase social alta: argumentos que explicitan la pertenencia de mujeres al estrato } \\
\text { socioeconómico alto. } \\
\text { 2. Mujer y espacio privado: argumentos que vinculan a la mujer con la casa y la cocina. }\end{array}$ \\
$\begin{array}{l}\text { 3. Familia feliz: argumentos que se refieren al rol de la mujer con la felicidad de la familia. } \\
\text { 4. Familia tradicional y estereotipada: argumentos que evidencian estereotipos de familias } \\
\text { tradicionales y biparentales. }\end{array}$ \\
$\begin{array}{l}\text { Negación } \\
\text { productivo } \\
\text { de la mujer }\end{array}$ & $\begin{array}{l}\text { 1. La mujer y roles reproductivos: argumentos que asocian a la mujer con ser madre y/o abuela, } \\
\text { encargada de la crianza. }\end{array}$ \\
\hline Funte:
\end{tabular}

Fuente: Elaboración propia.

Las relaciones de disociación pueden expresarse por: imcompatibilidad, exclusión, oposición, diferencia, discriminación y jerarquía.

Siguiendo esta nomenclatura, la construcción de la categoría mujer en anuncios publicitarios televisivos sobre alimentación, está dada por relaciones de asociación como de disociación. En cuanto a la asociación, aparecen argumentos pivotes que vinculan la categoría mujer con roles reproductivos, imagen corporal y la pertenencia a la clase socioeconómica alta. Se mantiene la lógica de asociación expresada en forma de equivalencia hacia los argumentos que se refieren al cuidado de la familia y al espacio privado, los que finalmente se relacionan en términos de unión con el rol social de la mujer en la alimentación. Por último, la familia tradicional estereotipada se muestra como pivote complementario al rol de la escuela y al uso de redes sociales.

Respecto de las principales disociaciones, el argumento pivote sobre la imagen corporal de la mujer, si bien es plenamente compatible con la normalidad nutricional y con la clase socioeconómica alta, igualmente se expresa en términos de diferencia con respecto a los roles reproductivos, la familia tradicional y con la ubicación exclusiva de la mujer en el espacio privado. En todos estos casos, los argumentos son de naturaleza diferente y no necesariamente relacionables entre sí. En las familias de clase económicamente alta, generalmente los roles reproductivos los cumplen las asesoras de hogar, por lo tanto, el espacio privado es ocupado principalmente por ellas. Del mismo modo, no todas las familias de clase alta dan cuenta del estereotipo tradicional, por el contrario, se observan múltiples realidades parentales.

A pesar de las diferencias presentes en los argumentos, desde este análisis gramatical, podemos observar que el discurso de los anuncios publicitarios presenta una clara coherencia con las proposiciones que refuerzan el estereotipo y rol que debe seguir cumpliendo la mujer en el contexto de las relaciones sociales, en el mantenimiento de la familia burguesa y en los roles reproductivos, tres ámbitos de control que confluyen y se refuerzan mutuamente de forma particular y explícita a través de la alimentación. A continuación algunas citas extraídas de los anuncios publicitarios que rearfiman lo anterior: "Lucchetti la pasta de mamá", "Está preparado para enfrentar lo que viene, los valores y el amor que le doy crecen con él. Nido, tu amor tu futuro", "Super pollo alimenta con cariño", "Jugoso Maggi, así cocino mi felicidad" y "Con Glucerna, sigues siendo tú". 


\subsection{Identificación de la estrategia discursiva}

De acuerdo al esquema $\mathrm{N}^{\circ} 1$ podemos observar que la estrategia discursiva se reconstruye a partir de las argumentaciones pivotales vinculadas al espacio privado, que se refieren a la negación de los roles productivos y a la familia burguesa. Por su parte, el control de las relaciones sociales situado en un plano público, como objeto discursivo vincula las argumentaciones pivotales que se asocian con: la corporalidad femenina, la socialización alimentaria, la complementareidad entre escuela y hogar, la normalidad nutricional y el rol de redes sociales.

En este sentido, la familia burguesa cumple la función de la conexión inter espacio y entre los objetos discursivos. A nivel de espacio privado refuerza la relación discursiva con la mantención de roles reproductivo, mientras que a nivel público el discurso se despliega a través de las argumentaciones que definen el control de las relaciones sociales. De este modo, la estrategia discursiva se ordena lógicamente de la siguiente manera:

\section{Figura $\mathrm{N}^{\circ} 1$ : Estrategia discursiva}

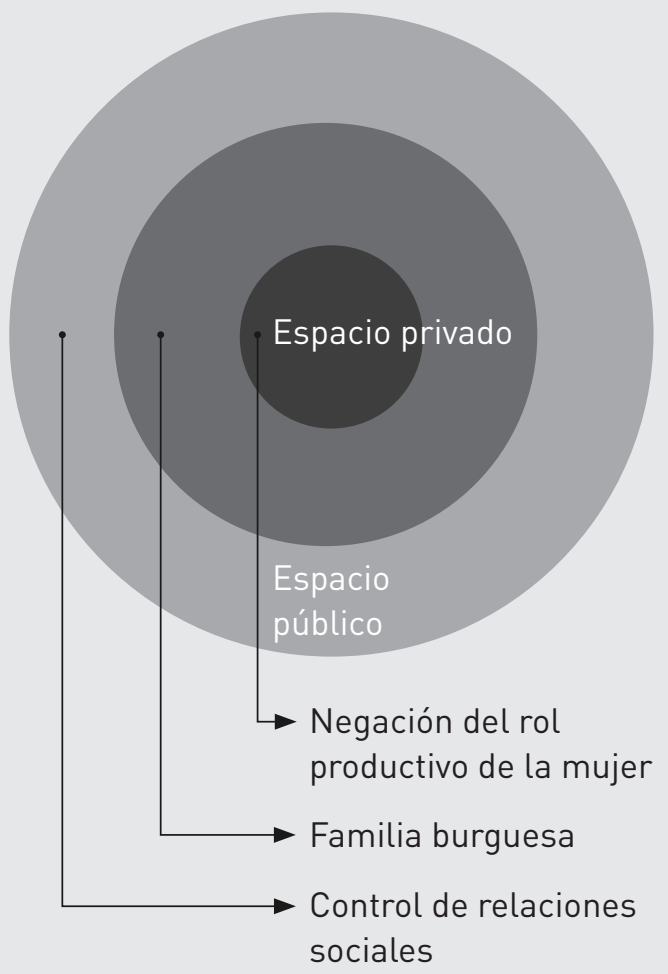

\section{Conclusiones}

De acuerdo al análisis realizado se observa cómo las lógicas de poder patriarcal materializadas en los argumentos construyen una categoría de mujer a partir de la alimentación. El anuncio publicitario como acto discursivo reiterado legitima roles y estereotipos propios del binarismo cisgénero el cual cruza argumentativamente los tres objetos discursivos analizados.

Respecto al control de las relaciones sociales, se reconoce a partir de los resultados que la alimentación se constituye en un importante medio para instaurar a nivel social la normalidad nutricional y estética en la mujer, desde una visión eurocéntrica asociada a belleza, delgadez y juventud. Dichos resultados son coincidentes con evidencia empírica que establece que en los anuncios publicitarios y televisivos en Chile aparece una autodefinición implícita como sociedad blanca (Amigo et al., 2016).

Respecto al mantenimiento de la familia burguesa, el mensaje publicitario la define como un espacio de reproducción del capitalismo global, mediante la asignación de roles reproductivos que expresan mecanismos de control sobre los recursos y productos asociados a la categoría mujer (Quijano, 2000). De este modo, los resultados obtenidos dialogan con estudios previos que reafirman la existencia de representaciones decorativas dadas a la mujer, mediante la asignación de roles de género de dependencia y al uso casi exclusivo del espacio privado (Velandia \& Rincón, 2013).

Por lo tanto, los resultados ratifican hallazgos previos que vinculan a la mujer con roles patriarcales y representaciones sexistas (Velandia \& Rincón, 2013; Espinar \& González, 2012). Dicha estereotipación de género identificada es igualmente coincidente con lo obtenido por Uribe et al. (2008) en una muestra de publicidad gráfica chilena, donde sus resultados indicaron que la publicidad asocia a las mujeres a productos de belleza y cuidado personal y a mayor dependencia emocional. Construyendo, en ambos casos, una imagen socialmente simplificada y rígida acerca de la mujer.

En este sentido, se evidencian los efectos de la publicidad de "la significación" bajo la relación signo-mercancía (Caro, 2014). Se concluye, que en la publicidad sobre alimentación en Chile, paradó- 
jicamente el alimento no es lo central del anuncio, lo que importa es la producción semiótica que se construye en torno a él. En otras palabras, la alimentación es el correlato en la construcción de la categoría mujer. Lo trascendental es el modelo semiótico capitalista que incluye ingredientes formales que intervienen en la sintaxis publicitaria, cuestión que deja en un segundo plano la mercancía en términos puros (Caro, 2002).

Ahora bien, dicha estructura semántica y pragmática comporta un sistema de significados que posibilitan la exteriorización y la manifestación formal de los condicionantes ideológicos propios de la modernidad colonialista, donde el cuerpo de la mujer pasa a ser la principal mercancía (Cobo, 2015). Esto implica que a través del discurso publicitario se introducen las condiciones no solo ideológicas, sino que también sociales e institucionales, las que según Giménez (1981) establecen los límites del discurso: lo que puede y no puede decirse acerca de la mujer, por consiguiente lo que debe y no debe consumirse alimentariamente.

Los anuncios publicitarios de alimentación en Chile se articulan en torno a una estrategia discursiva a partir de diversos enunciados (como aserciones, certezas, deónticos, factitivos) los que afirman, niegan, establecen verdades y deberes, respecto a las expresiones, representaciones y funcionalidad otorgadas al género femenino. Asimismo, dicha estrategia ubica a la mujer en un espacio, tiempo y contexto simbólico determinado. Una serie de dispositivos lógicos semánticos, que gramaticalmente impregnan un conjunto de acciones productoras de una realidad social.

Por lo tanto, las argumentaciones como componentes frásicos o modalizados pasan a cobrar una existencia global de sentido (Greimas \& Courtés, 1982). Bajo un análisis interpretativo de los resultados se reconoce que el predicado modal, correspondería a los enunciados argumentativos (Tabla $\left.N^{\circ} 4\right)$, los que pueden ser definidos por su finalidad transitiva, como argumentaciones pivotales (Tabla $N^{\circ} 5$ ) capaces de alcanzar otro enunciado mayor dotado de sentido, la articulación de la estrategia discursiva (Figura $\mathrm{N}^{\circ} 1$ ).

Los argumentos pivotales pueden asumir diversas relaciones de asociación y disociación entre ellos, dando cuenta de niveles de coherencia o de con- tradicciones en la lógica interna del argumento, cuestión que nos lleva a concluir que el discurso publicitario sobre alimentación estaría más allá de lo verdadero y de lo falso (Baudrillard, 1974). De ahí, que "la realidad no termine siendo otra cosa sino el modelo que se habla a sí mismo" (Baudrillard 1974, p.181). Con lo anterior se concluye que la semiosis inscrita en el anuncio publicitario, es un lenguaje puesto en acto en el cual se materializan relaciones de poder y de control con las cuales funcionan las sociedades, cuestión que reafirma su carácter ideológico.

Atendiendo al enfoque feminista del estudio, se concluye, a partir de los resultados y de algunos datos de contexto, que la publicidad televisiva de alimentos no está otorgando una posicionalidad discursiva a una gran mayoría de mujeres. Por ejemplo, está invisibilizando a aquellas mujeres que no se representan con la maternidad. Al respecto, cifras vitales proporcionadas por el Instituto Nacional de Estadísticas (INE, 2017) muestran no solo una reducción del número de hijos, sino que además una cada vez mayor postergación de la maternidad en el ciclo de vida de las mujeres chilenas.

El discurso publicitario sobre alimentación tampoco está representando a quienes no adhieren a la normalidad estética y nutricional. En Chile el $32 \%$ de mujeres mayores de 18 años son obesas, liderando el ranking a nivel latinoamericano (FAO, OMS \& UNICEF, 2017). Más aun, dicho porcentaje se concentra fuertemente en el grupo de mujeres chilenas con bajo nivel educativo (Ministerio de Salud de Chile, 2010), población que tampoco aparece representada en los anuncios publicitarios.

La publicidad también excluye a mujeres que además de cumplir roles reproductivos, desempeñan funciones productivas. Si bien en Chile, la proporción de mujeres sustentadoras del hogar es inferior a la de los hombres, 6 de cada 10 mujeres si participan del mercado laboral, aunque en desigualdad de condiciones. Reciben ingresos más bajos y ocupan menos cargos de responsabilidad (INE, 2017).

El principal aporte de este estudio fue el diseño de una metodología que permitió reconocer las determinaciones predicativas, las argumentaciones en función de las diferentes modalizaciones pre- 
sentes en los objetos discursivos, las relaciones de asociación y disociación entre los argumentos pivotales y la lógica general de la estrategia discursiva de los anuncios publicitarios sobre alimentación.

Con el análisis realizado se concluye que la televisión en la era digital sigue socializando "viejas prácticas" en torno a la construcción de la categoría mujer, pero lo hace a partir de "nuevas semióticas". Un conjunto de modalizaciones que aseguran la reproducción del modelo económico como "semio capitalista" (Caro, 2002).
Por último, se evidencia la necesidad de continuar desarrollando investigaciones sobre publicidad de alimentos desde un análisis feminista, ampliando el estudio de objetos discursivos que permitan explicitar el carácter ideológico que está operando a modo de verdad en la construcción publicitaria de la categoría mujer del tercer mundo.

\section{Referencias}

Amigo, B., Bravo, M. C., Sécail, C., Lefébure, P., \& Borrell, A. (2016). Televisión, diversidad y hegemonía cultural: un estudio comparado de los estereotipos étnicos dominantes en los sistemas televisivos de Chile y Francia. Cuadernos. info, (39), 151-164.

Arias, A. \& Sánchez, A. (2017). La cimentación social del concepto mujer en la red social Facebook. Revista de Investigación Educativa, 35(1), 181-195.

Baudrillard, J. (1974). La sociedad de consumo. Sus mitos, sus estructuras. Barcelona: Plaza y danés.

Butler, J. (2004). Undoing Gender. New York \& London: Routledge. https://doi. org/10.4324/9780203499627

Butler, J. (2002). Cuerpos que importan: sobre los límites materiales y discursivos del sexo. Buenos Aires: Paidós.

Cabrera, Y. (2010). El cuerpo femenino en la publicidad. Modelos publicitarios: entre la belleza real, la esbeltez o la anorexia. Icono14, 8(3), 11, 223-243.

Cáceres, M. Ruiz, J., \& Brändle G. (2011). El uso de la televisión en un contexto multipantallas: viejas prácticas en nuevos medios. Anàlisi: quaderns de comunicació i cultura, (43), 21-44.

Caro, A. (2014). Comprender la Publicidad para Transformar la Sociedad. Cuadernos.info, (34), 39-46. https://dx.doi.org/10.7764/cdi.34.584

Caro, A. (2002). La publicidad de la significación (marco, concepto y taxonomía). Madrid: Servicio de Publicaciones de la Universidad Complutense. Disponible en http:// www.ucm.es/eprints/1788/.

Castillo, B. (2006). La sociedad de consumo y los trastornos de la conducta alimentaria. Trastornos de la conducta alimentaria (4), 321-335.

Cobo, R. (2015). El cuerpo de las mujeres y la sobrecarga de sexualidad. Investigaciones feministas, 6, 7-19.

Consejo Nacional de Televisión de Chile (CNTV) (2016). Anuario estadístico del Consejo Nacional de Televisión Chile. Santiago. 
Del Valle, C. (2015-2019): “La construcción del imaginario social de la justicia en los relatos periodísticos publicados por el diario El Mercurio de Chile, entre 1850 y 2014, en el contexto del conflicto Estado-nación y pueblo mapuche: Continuidades y cambios". Proyecto CONICYT-CHILE/FONDECYT No 1150666.

Díaz-Méndez, C. \& González-Álvarez, M. (2013). La problematización de la alimentación: un recorrido sociológico por la publicidad alimentaria (1960-2010"). Empiria. Revista de metodología de las ciencias sociales, (25), 121-145. https://doi. org/10.5944/empiria.25.2013.3800.

Duch, L. \& Mèlich, J. (2000). Escenarios de la corporeidad. Madrid: Editorial Trotta SA.

Espinar, E. \& González, C. (2012). Representaciones de género en la publicidad de alimentos: un análisis de contenido. Cuestiones de género: de la igualdad y la diferencia. N. 7, pp. 227-245.

FAO, OMS \& UNICEF. (2017). El estado de la seguridad alimentaria y la nutrición en el mundo 2017. Fomentando la resiliencia en aras de la paz y la seguridad alimentaria. Roma: FAO.

Fidler, R. (1998). Mediamorfosis: comprender los nuevos medios. Buenos Aires: Gránica.

Giménez, G. (1981). Poder, estado y discurso: perspectivas sociológicas y semiológicas del discurso político-jurídico. México: Universidad Autónoma de México.

Greimas, A. \& Courtés, J. (1982). Semiótica: diccionario razonado de la teoría del lenguaje. Madrid:Gredos.

Instituto Nacional de Estadísticas (INE). (2017). Anuario de Estadísticas Vitales. INE-Chile.

Jódar , J. (2010). La era digital: nuevos medios, nuevos usuarios y nuevos profesionales. Razón y Palabra, 15 (71).

Loscertales, F. \& Núñez, T. (2009). La imagen de las mujeres en la era de la comunicación. Ic revista científica de información y comunicación, (6), 427-462.

Márquez, M. (2007). Análisis semiótico del concepto actual de belleza en la publicidad dirigida a la mujer. Trastornos de la conducta alimentaria, (5), 483-506.

Ministerio de Salud de Chile (2010). Encuesta Nacional de Salud. Chile 2009-2010.

Mohanty, Ch.(2008). “Bajo los ojos de occidente. Academia Feminista y discurso colonial”. In: Suarez, L. y Hernández, A. Descolonizando el Feminismo: Teorías y Prácticas desde los Márgenes. Madrid: Cátedra, 112-161.

Muñiz, E. (2014). Pensar el cuerpo de las mujeres: cuerpo, belleza y feminidad. Una necesaria mirada feminista. Sociedade e estado, 29(2), 415-432. http://dx.doi. org/10.1590/S0102-69922014000200006

Navarro, M. \& Marín, M. (2013). Análisis bibliométrico de la investigación sobre mujer y publicidad: diferencias en medios impresos y audiovisuales. Comunicar, 21(41), pp. 105-114. http://dx.doi.org/10.3916/C41201310.

Pedraza, Z. (2009). Derivas estéticas del cuerpo. Desacatos, (30),75-88.

Pérez, J. (2008). La sociedad multipantallas: retos para la alfabetización mediática. Comunicar: Revista científica iberoamericana de comunicación y educación, (31), 1525. 
Quijano, A. (2000). El fantasma del desarrollo en américa latina. Revista venezolana de economía y ciencias sociales, (6) 2, pp. 73-90

Quintero, P. (2013). Desarrollo, modernidad y colonialidad. Revista de antropología experimental, 13, 67-83. Universidad de Jaén España.

Repiso, R., Fernández, I. \& Lloves, B. (2015). Ranking de anuncios y agencias de publicidad en Chile. Flaro: revista teórica del Departamento de Ciencias de la Comunicación, 1(21), 36-52.

Ribas, M. \& Todolí, J. (2008). La metáfora de la mujer objeto y su reiteración en la publicidad. Discurso \& sociedad, 2(1), 153-169.

Royo-Vela, M. Aldas-Manzano, J., Küster, I., \& Vila, N. (2008). “Adaptation of marketing activities to cultural and social context: gender role portrayals and sexism in spanish commercials". Sex roles, 58(5-6), pp. 379-390. https://doi.org/10.1007/ s11199-007-9341-y

Santa Cruz, E. (2017). Derrotero histórico, tendencias y perspectivas de la televisión chilena. Comunicación y Medios, (35), 08-21. https: doi:10.5354/0719-1529.2017.45906

Thompson, J. (1998). Ideología y cultura moderna. México: UAM-Xochimilco.

Uribe, R., Manzur, E., Hidalgo, P. \& Fernández, R. (2008). Estereotipos de género en la publicidad: un análisis de contenido de las revistas chilenas. Academia. Revista Latinoamericana de Administración, (41), 1-18.

Velandia, A. \& Rincón, J. (2013). Estereotipos y roles de género utilizados en la publicidad transmitida a través de la televisión. Universitas Psychologica, 13(2), 517-527.

- Sobre los autores:

Carolina Godoy Berthet es socióloga, magíster en Desarrollo Humano Local y Regional, doctora (C) en Ciencias Sociales. Áreas de investigación: alimentación, medios de comunicación, cuerpo y mujer.

Marianela Denegri Coria es Psicóloga, magíster en Psicopedagogía, doctora en psicología. Áreas de investigación: consumo y ciudadanía económica, educación económica y financiera, psicología económica.

Berta Schnettler Morales es Ingeniera agrónoma, doctora en Ciencias Empresariales. Áreas de investigación: alimentación y familia, satisfacción con la alimentación, comportamientos de compra de productos agroalimentarios.

Mauricio Alarcón Silva es Sociólogo, Magíster en Desarrollo Humano Local y Regional, estudiante del programa de Doctorado en Comunicación UFRO-UACH. Áreas de investigación: análisis de discurso, desarrollo y políticas públicas.

- ¿Como citar?

Godoy, C., Denegri, M., Schnettler, B. \& Alarcón, M. (2019). La mujer en la publicidad televisiva de alimentos en Chile: una aproximación feminista desde el análisis argumental del discurso. Comunicación y Medios, (40), 68-81. 